\title{
Clinical Management and Evaluation of White Spot Lesions: A Report of 11 Cases
}

\author{
Domenico Aiello', Riccardo Pulcini'², Sandro Sestito³, Michele Mario Figliuzzi'1, Sergio Paduano ${ }^{1}$ \\ ${ }^{1}$ Department of Health Sciences, "Magna Graecia” University of Catanzaro, Catanzaro, Italy \\ ${ }^{2}$ Department of Medical, Oral and Biotechnological Sciences, University of Chieti, Chieti, Italy \\ ${ }^{3}$ Privat Contractor, Italy \\ Email: riccardopulcini@outlook.com
}

How to cite this paper: Aiello, D., Pulcini, R., Sestito, S., Figliuzzi, M.M. and Paduano, S. (2020) Clinical Management and Evaluation of White Spot Lesions: A Report of 11 Cases. Open Journal of Stomatology, 10, 156-173.

https://doi.org/10.4236/ojst.2020.107016

Received: May 7, 2020

Accepted: July 13, 2020

Published: July 16, 2020

Copyright $\odot 2020$ by author(s) and Scientific Research Publishing Inc. This work is licensed under the Creative Commons Attribution International License (CC BY 4.0).

http://creativecommons.org/licenses/by/4.0/

\begin{abstract}
Introduction: Today's society is always more interested to the concept of aesthetics. The patients frequently ask to dentist to resolve unaesthetic problems of teeth, in particular that of the upper frontal group. The WSLs are enamel white alterations due to alteration during the demineralization and remineralization of enamel. This effect is caused by alteration of the $\mathrm{pH}$ in the oral cavity and buffer action of saliva. An alteration of this relationship leads to a progressive demineralization of enamel until the formation of a dental cavitation. Materials and Methods: For this study are selected 11 patients, of which 3 men and 8 women, with total of 17 WSLs. The inclusion criteria included WLSs with ICDAS $=2$ and WLSs caused by hypomineralization of traumatic origin. These patients were subjected to treatment with infiltrating resin according to operative procedure. Discussion: The therapy with infiltrating resin gave great results in 12 lesions out of 17 . In the lesions where there weren't a complete remission we obtained a great aesthetic improvement and a good reduction of lesions. The follow up could improve the result after a better rehydration of hard tissue. Conclusions: With a correct selection of cases and good operative procedure, the use of the micro-infiltrative technique by low viscosity resin is a good procedure to resolve WSLs problems of non-orthodontic origins. Other studies with a larger sample are required to validate this clinical approach.
\end{abstract}

\section{Keywords}

WSL, Microinfiltration, Demineralization, Icon, Enamel

\section{Introduction}

Nowadays society is more interested in aesthetics, social media have often exacer- 
bated the concept of aesthetics [1] and more and more patients go to the dentist in order to resolve the imperfections of the dental structure, especially in the area of the teeth of the upper frontal group [2]. At the dental enamel level we can divide the dyschromias into: extrinsic problems [3], due to pigmentations on the outermost layer of the enamel by chromogenic agents caused by smoking or contained in foods such as coffee, soya, etc. Instead intrinsic problems involve multiple layers or less internal layers of the enamel and they are divided in pre-eruptive and post-eruptive alterations [4] [5]. The pre-eruptive problems are alterations that occur on the enamel during its formation and can be divided into:

- Fluorosis lesions: they are caused by an excessive absorption of fluoride, this alteration normally involves a group of teeth rather than individual elements. According to the US National Institute of Dental Research, the prevalence of this alteration represents $9 \%$ of cases of fluorosis in the 15 -year-olds from 1986 to 2002 [6].

- Traumatic hypomineralization lesions: they are lesions caused by trauma on milk teeth, often unrecognized as they normally occurred in the first years of life. Its prevalence is estimated at around $5.2 \%$ of the population [7]. These lesions are normally on individual dental elements and occur asymmetrically compared to the contralateral ones. At a clinical level, they can present with more or less defined and circumscribed whitish spots. Histologically these are also presented as hypomineralization zone of the superficial third of the enamel coated with a layer of well mineralized enamel which is formed after the tooth eruption due to a remineralization process by saliva. The lesion can present itself with an irregular pattern forming acute angles with the rest of the healthy enamel or with a convergent trend with respect to the healthy enamel forming obtuse angles.

- MIH lesions (molar-incisor hypomineralization): they are lesions that purely affect the first definitive molars (FPM) and they can be associated with lesions on the permanent incisors (PI).This lesion can occur with various forms of severity (Chawla severity index) [8], the prevalence of MIH stands around $14.2 \%[9]$.

The post-eruptive problems, on the other hand, are mainly given by carious problems and are generally defined as white spots lesions (WSLs) [10] [11] [12] [13]. WSLs are white alterations of the enamel due to an alteration in the demineralization-remineralization mechanism of the enamel. The alteration of this relationship leads to a progressive demineralization of the enamel until complete dental cavitation. The prevalence of these alterations is estimated around $24 \%$ of the population [14] but this percentage rises significantly in patients with braces, with variable percentage reaching $97 \%$ [15], on average at least $46 \%$ of patients develop at least 1 wsl at 12 months [16]. These lesions can be classified according to the ICDAS II scale in grades 1 and 2 [17] [18]. All the lesions listed above with a white appearance are due to an optical effect of light refraction in the enamel, a healthy enamel has a refractive index of light equal to that of hydroxyapatite (RI 
= 1.63), hypocalcification creates voids inside the enamel that fill with air $(\mathrm{RI}=1)$ [19] [20] and organic fluids ( $R I=1.33$ ), for this reason if the lesions are dried they result more evident. Over the years the therapy of these lesions has made use of various minimally invasive techniques such as remineralization using topical remineralizing substances [21] [22] [23], dental bleatching [24] and dental microabrasion [25] that eliminates the lesion at the expense of a lot of mineralized tissue. In recent years the technique of major election in the treatment of white lesions has been certainly the infiltration technique using low viscosity resins (Icon, DMG) [4] [20] [26], this technique has been the first to provide for the removal of mineralized tissue using a new chemical etchant (hydrochloric acid $15 \%$ ) able to completely remove the mineralized surface layer and infiltrate the lesion by means of a low viscosity resin, blocking the progression of the carious pathology with a protective layer of resin. In addition to prevent the progression of the injury, this technique promotes an immediate improvement of the aesthetic aspect because the infiltrative resin has a refractive index $(\mathrm{RI}=1.44)$ very similar to that of hydroxyapatite. Recently an association between this technique preceded by a chemical microabrasion (opalustre, ultradent) [27] seems to have a synergistic effect on lesions more refractory to treatment.

The purpose of this scientific research was to expose a series of cases of WSLs treated by infiltrative technique or infiltrative technique associated with microabrasion and evaluate the result immediately after treatment.

\section{Materials and Methods}

- ICON Infiltrant: chemical composition: TEDMA (triethyleneglycol dimethacrylate) $70 \%$ - 95\%, Camphoro Quinone $<2.5 \%$;

- ICON Etch: hydrochloric acid 15\%;

- ICON Dry: ethanol alcohol.

\subsection{Operating Procedure Application of Icon Infiltring Resin}

The study was conducted in accordance with the Declaration of Helsinki, and the protocol was approved by the Ethics Committee of Catanzaro.

The sample comprised patients selected from Magna Græcia University's dental clinic and orthodontic private practice. Patients were treated according to the following protocol.

\section{Phase one:}

The dental surfaces were cleaned with a specific paste without fluorine (CleanPolish Kerr), positioning the dam to isolate the operating field. In two patients it was necessary to perform a micro abrasion of the enamel with a $3 \mathrm{M}$ disc, patients are indicated in Table 1.

\section{Phase two:}

The ICON Etch product $(15 \% \mathrm{HCl})$ was applied for two minutes on the surfaces concerned, adapted to them by means of a special syringe with the final brush part to better homogenize the product (Figure 1). 
Table 1. Summary scheme of treated patients.

\begin{tabular}{cccc}
\hline PATIENT & WSL & $\begin{array}{c}\text { ICON NUMBERS OF } \\
\text { APPLICATION }\end{array}$ & $\begin{array}{c}\text { MICROABRASION } \\
\text { REQUEST }^{*}\end{array}$ \\
\hline 1 & 2 & 3 & No \\
2 & 2 & 3 & No \\
3 & 1 & 3 & Si \\
4 & 2 & 3 & No \\
5 & 1 & 3 & No \\
6 & 2 & 3 & No \\
7 & 1 & 3 & Si \\
8 & 1 & 3 & No \\
9 & 2 & 3 & No \\
10 & 2 & 3 & No \\
11 & 2 & 3 & No \\
12 & 1 & 3 & No \\
\hline
\end{tabular}

*Previously described.

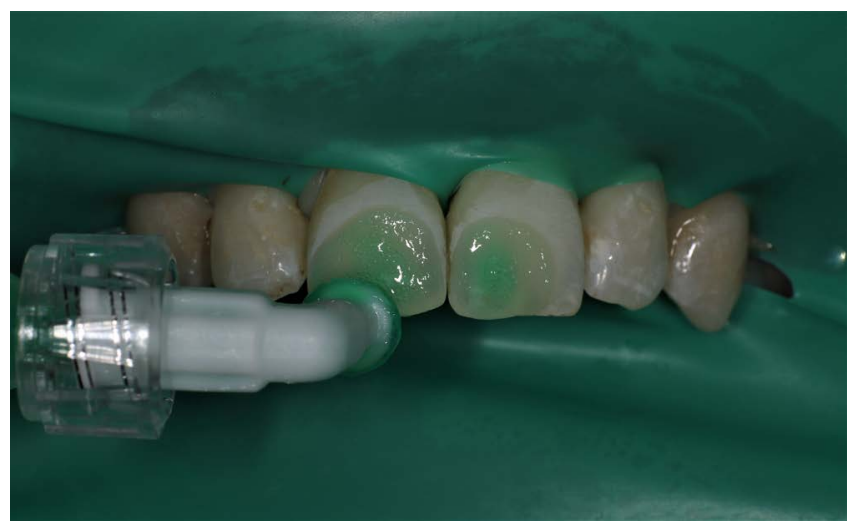

Figure 1. Gel Application.

After applying ICON Etch, it was removed by aspirating it from the surfaces then rinsed with water for 30 seconds (Figure 2 ) and then dried.

\section{Phase three:}

After being carefully dried, ICON Dry was applied on the surfaces (ethanol) (Figure 3) to obtain complete dehydration, and therefore favor the infiltration of the resin, and to have a preview of the treatment. This ethanol application evaporates quickly, leaving the teeth with a chalky appearance (Figure 4).

We repeated this procedure three times on each patient involved.

\section{Phase four:}

After making the evaluation of the WSL we used ICON Infriltrant to carry out the resin infiltration with a special tip with a brush for 3 minutes (Figure 5) and removing excess with a cotton roller.

Then we light-cured for 40 seconds (Figure 6). 


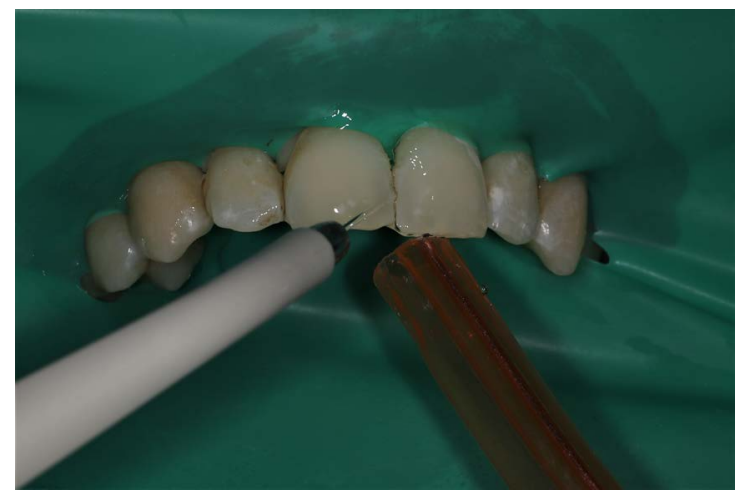

Figure 2. Wash the surface.

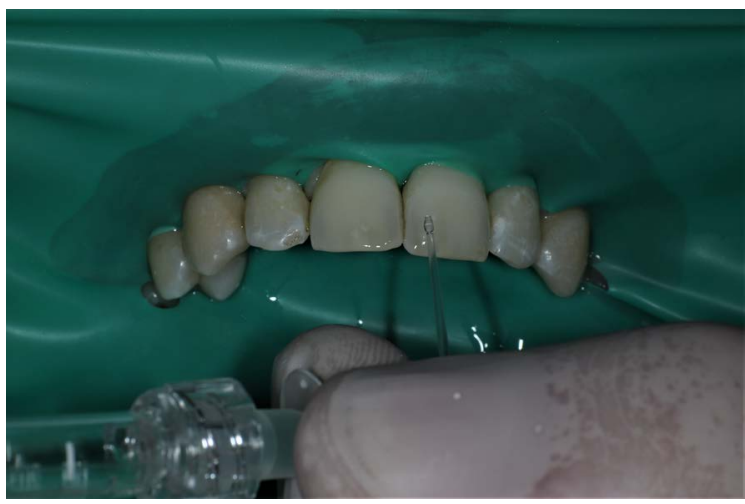

Figure 3. Application ethanol.

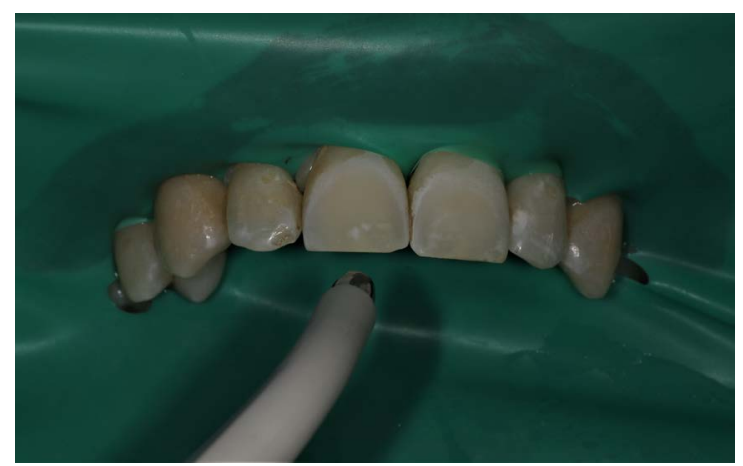

Figure 4. Air after ethanol.

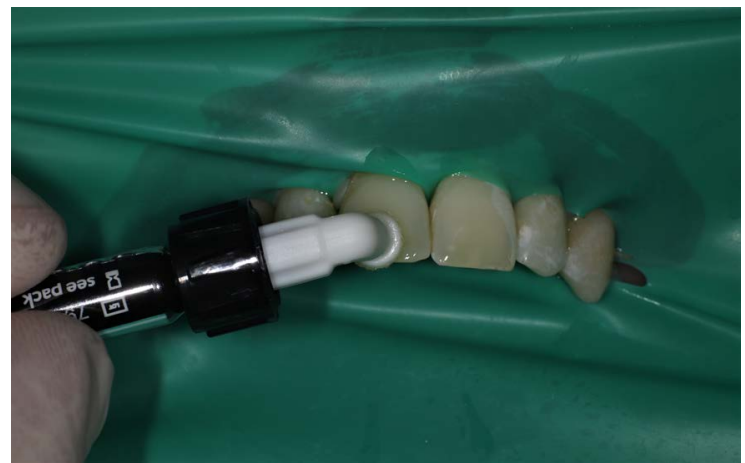

Figure 5. Resin application. 


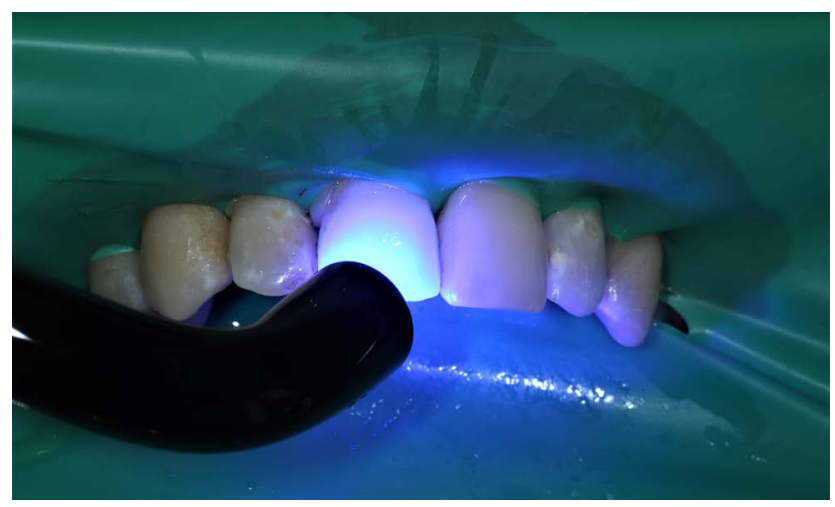

Figure 6. Curing light.

We performed a new resin infiltration for one minute and light-cured for another 40 seconds.

Then a two-step polishing was carried out with two Comet rubbers contained in set 4669 at $6000 \mathrm{rpm}$ (Figure 7).

At the end we removed the dam and photographed the post-treatment patients (Figure 8, Figure 9).

For this study 11 patients were selected, including 3 males and 8 females between the ages of 10 and 40 (average age 25 years), with 17 WSL in total.

\section{Inclusion criteria:}

- WSLs of carious origin (ICDAS $=2)$

- WSLs from hypomineralization of traumatic origin

\section{Exclusion criteria:}

- Cavitated lesions (ICDAS $\geq 3$ )

- MIH lesions

- Lesions of imperfect amelogenesis

- Fluorosis lesions

- Yellow or Brown stain

Of the selected cases, two were subjected to micro abrasion using a fine grain $3 \mathrm{M}$ disc (Soflex Pop On 2382SF) at a speed of 20,000 rpm.

The evaluation photographs were taken pre and immediately after the operation, using the Reflex digital camera (Canon $800 \mathrm{~d}$ ).

All patients were treated according to the protocol previously described with three applications as it can be seen from the table.

\subsection{Case Series}

- Patient 1: woman, 20 years old, presented at our dental clinic of "Magna Græcia" University in Catanzaro. In the anamnesis there were not previous orthodontic therapies. The patient had WSLs in the area of the third incisal distal area of the 11 and third incisal distal area and the middle third distal area of the 21, both lesions had irregular margins. After the treatment we obtained the complete removal of the WSLs (pre-treatment Figure 10, post-treatment Figure 11). 


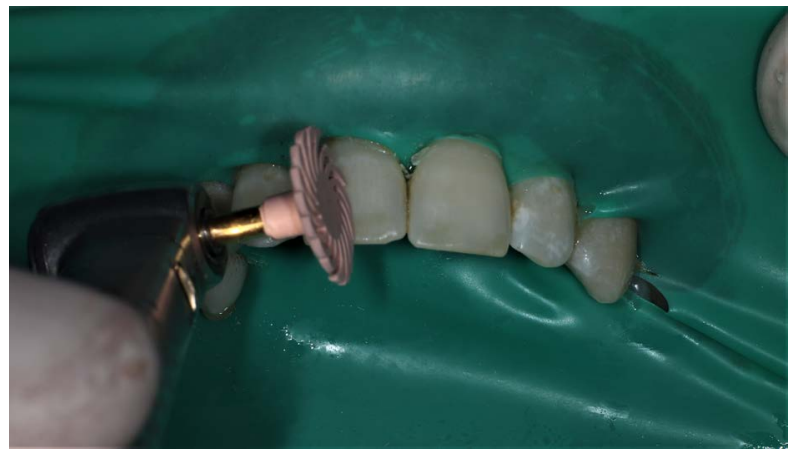

Figure 7. Polish surface.

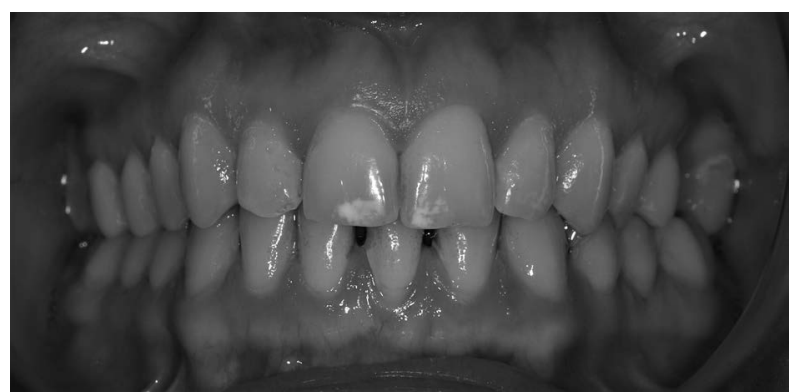

Figure 8. Pre BW.

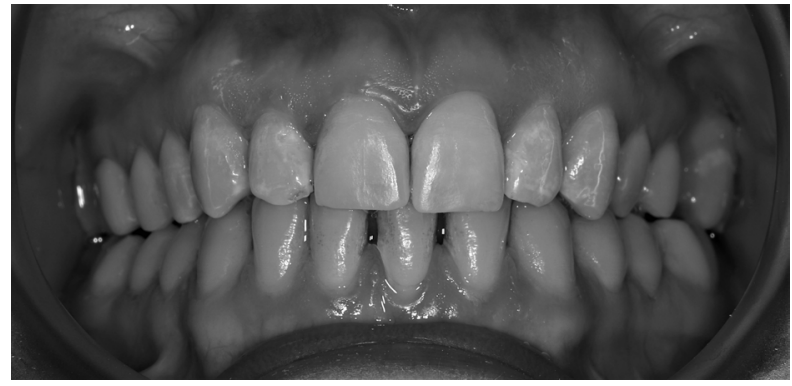

Figure 9. Post BW.

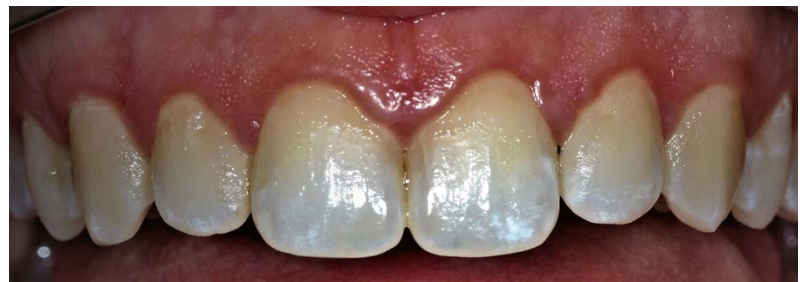

Figure 10. Patient 1 before.

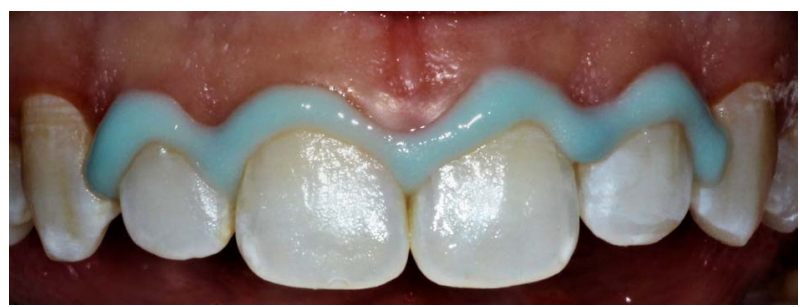

Figure 11. Patient 1 after. 
- Patient 2: woman, 22 years old, presented at our dental clinic of "Magna Græcia" University in Catanzaro. In the anamnesis there were not previous orthodontic therapies. The patient had a lesion extended over the entire middle and distal incisal portion of the 11 with irregular margins and a smaller and more limited WSL in the area of the incisal and distal third of 21.

The 21 also had a discolouration of traumatic origin but the patient didn't want to perform internal bleaching procedures. At the end of the treatment it can be seen a good resizing of the lesions mostly on 21 but this can be due to dehydration (pre-treatment Figure 12, post-treatment Figure 13).

- Patient 3: woman, 22 years old, presented at our dental clinic of "Magna Græcia" University in Catanzaro. In the anamnesis there were not previous orthodontic therapies. The patient had a very extensive WSL in the middle and incisal area up to the interdental contact point, the margins of the lesion were well defined. Before the infiltration, the patient was subjected to a microabrasion for about 30 seconds, because of the doubtful nature of the lesion, probably of traumatic origin.

In the immediate post-treatment, a complete disappearance of the lesion can be seen (pre-treatment Figure 14, post-treatment Figure 15).

- Patient 4: woman, 11 years old, comes to our attention at the dental clinic of "Magna Græcia" university in Catanzaro for orthodontic examination. The patient presented two WSLs extended on elements 11 and 21 in the incisal area from the distal area to the mesial area without interruption, the lesions had undefined margins. After infiltrative therapy, complete resolution of the lesions was achieved (pre-treatment Figure 16, post-treatment Figure 17).

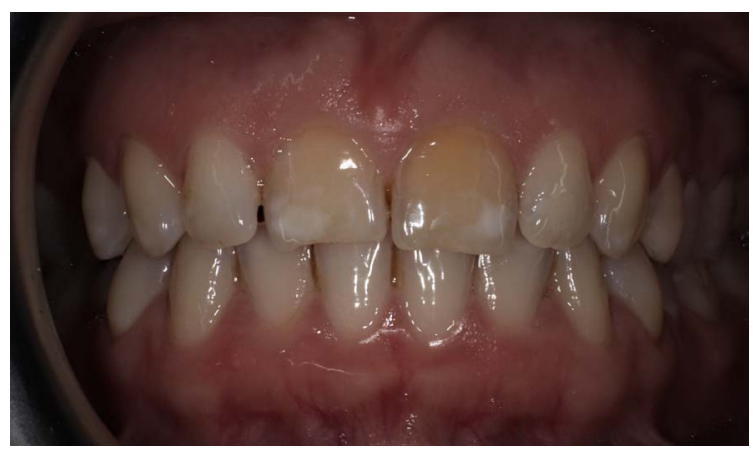

Figure 12. Patient 2 before.

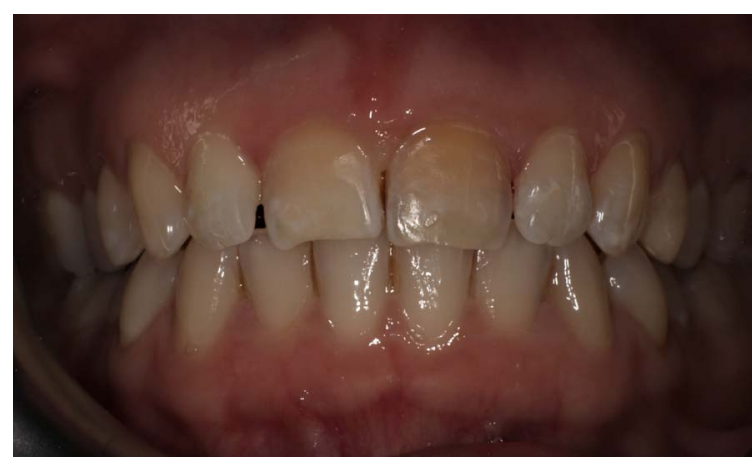

Figure 13. Patient 2 after. 


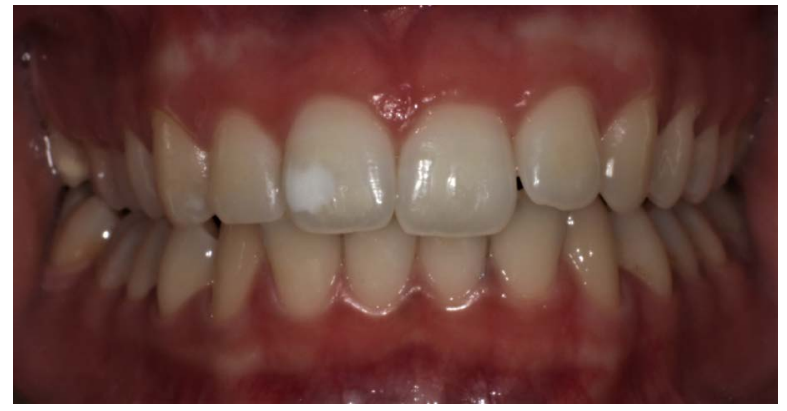

Figure 14. Patient 3 before.

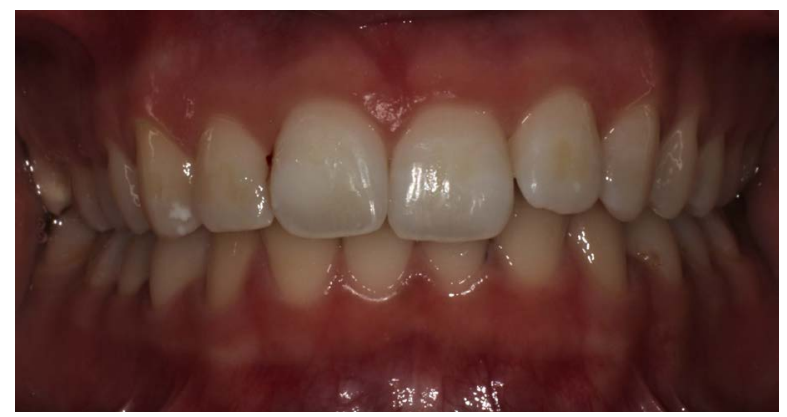

Figure 15. Patient 3 after.

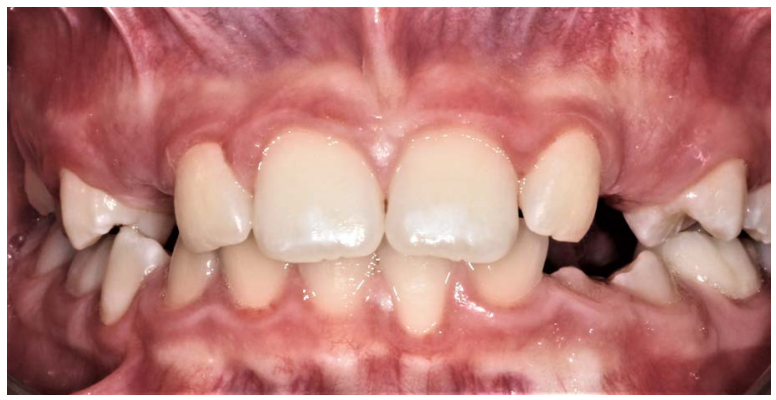

Figure 16. Patient 4 before.

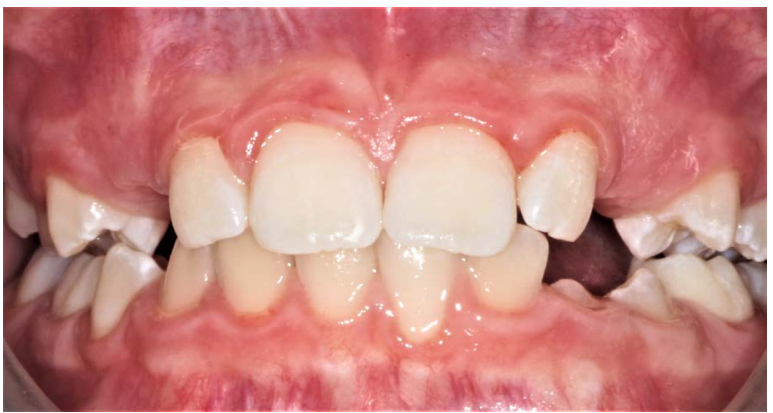

Figure 17. Patient 4 after.

- Patient 5: man, 21 years old, the patient came to our attention in a private practice due to an unattractive lesion of element 21 in the area of the middle incisal third, according to the anamnesis he was previously subjected to fixed orthodontic therapy but the lesion seemed to be of traumatic origin because of the well-defined margins and the area of presentation of the lesion. At the 
end of the treatment the 21 shows the complete removal of the lesion and an excellent aesthetic result (pre-treatment Figure 18 post-treatment Figure 19).

- Patient 6: woman, 40 years old, no previous orthodontic therapy. The patient came to our attention in a private practice due to a double WSL on element 11; it was very marked by an irregular appearance and defined margins. Because of the probable traumatic origin of the lesion, the dental element was subjected to a micro abrasion before infiltration.

After the treatment, the double WSL was not resolved definitively but certainly an important aesthetic improvement was achieved (pre-treatment Figure 20, post-treatment Figure 21).

- Patient 7: man, 18 years old, no previous orthodontic therapy. He comes to our dental clinic in Catanzaro University of "Magna Græcia" for unattractive WSL in the central and incisal area of element 21 , the lesion had fairly well defined margins for this reason we treated it as a traumatic lesion, the patient was subjected to a microabrasion procedure before infiltration. The therapy allowed to fully resolve the lesion with a high aesthetic improvement (pre-treatment Figure 22, post-treatment Figure 23).

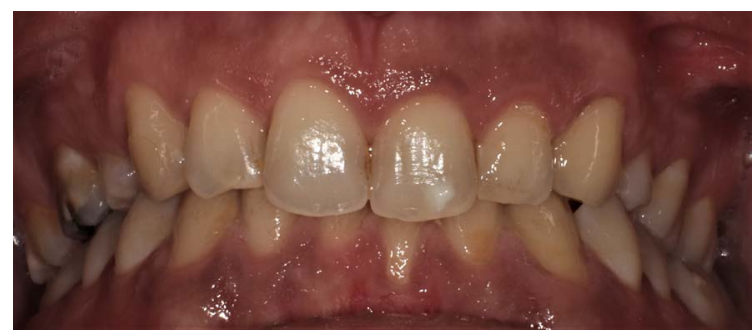

Figure 18. Patient 5 before.

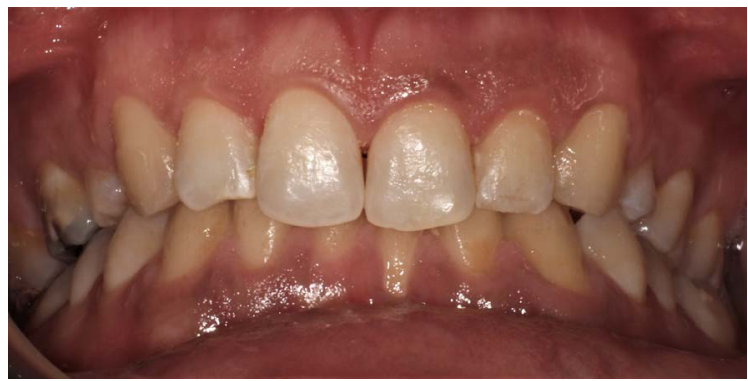

Figure 19. Patient 5 after.

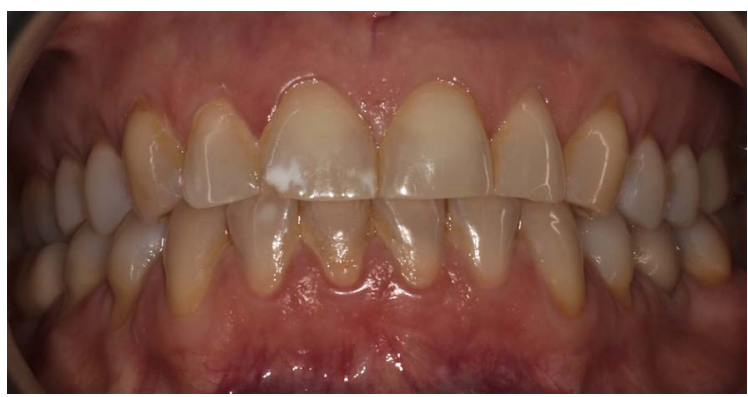

Figure 20. Patient 6 before. 


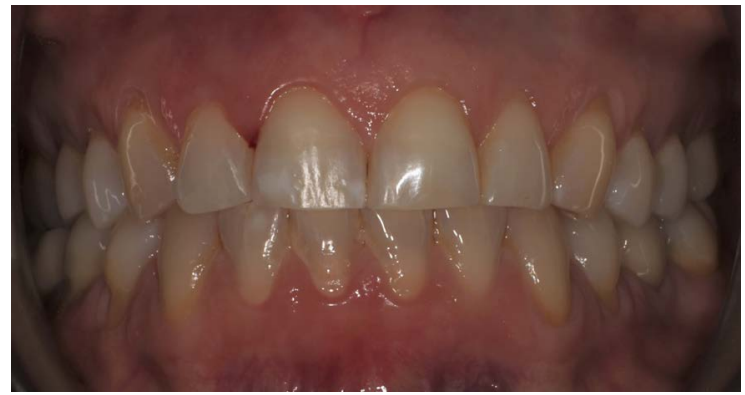

Figure 21. Patient 6 after.

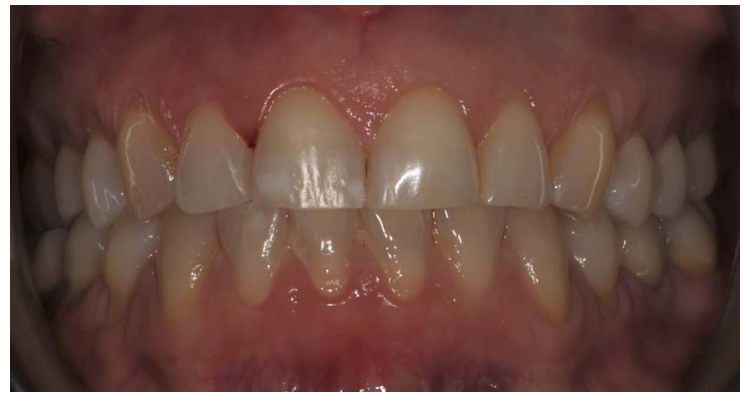

Figure 22. Patient 7 before.

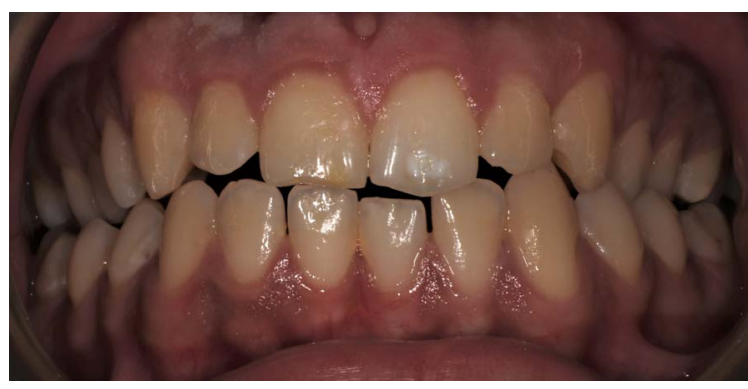

Figure 23. Patient 7 after.

- Patient 8: woman, 18 years old, no previous orthodontic therapy. She came to the private practice for anti-aesthetic wsl in the mid-incisal area of 11, the lesion had little defined and irregular margins. After the micro-infiltrative treatment, the complete resolution of the WSL was obtained with excellent aesthetic results. (pre-treatment Figure 24, post-treatment Figure 25).

- Patient 9: man, 30 years old, previous orthodontic therapy with transparent aligners. He presented himself to our observation at the private practice for some WSLs, one very extensive on the mid-incisal area in zone 11, and a second one less extensive on the incisal area of 21. Both lesions had poorly defined and irregular margins.

In the post-treatment, a complete removal of the lesions can be seen, allowing an improvement in dental aesthetics (pre-treatment Figure 26, post-treatment Figure 27).

- Patient 10: woman, 32 years old, no previous orthodontic therapy. She came to the private practice for two WSLs. The first lesion had an extension over the 
entire middle and mesial incisal part of element 21. The second WSL, with reduced size, involved only the medial incisal portion of element 21 . Both WSLs had irregular shapes and poorly defined margins. In the immediate post therapy, a complete disappearance of the lesions and a good aesthetic result can be seen (pre-treatment Figure 28, post-treatment Figure 29).

- Patient 11: woman, 18 years old, according to anamnesis no previous orthodontic therapy was made. The patient came to our observation in a private practice due to two very unattractive WSLs. The first WSL was less extensive than the second one, and it included part of the incisal surface from mesial to distal on the 11 element. The second WLS was more extensive and it included the entire incisal third from mesial to distal. The lesions had irregular shapes but the margins were well defined. At the end of the therapy a reduction can be noticed but not a complete remission of the lesions, probably a microabrasion previous to the therapy would have improved the aesthetic result (pre-treatment Figure 30, post-treatment Figure 31).

- Patient 12: man, 38 years old, no previous orthodontic therapy. He comes to our dental clinic in Catanzaro University of "Magna Græcia” for unattractive WSL in the distal area of element 12, After infiltrative therapy, complete resolution of the lesions on dental element (pre-treatment Figure 32, posttreatment Figure 33).

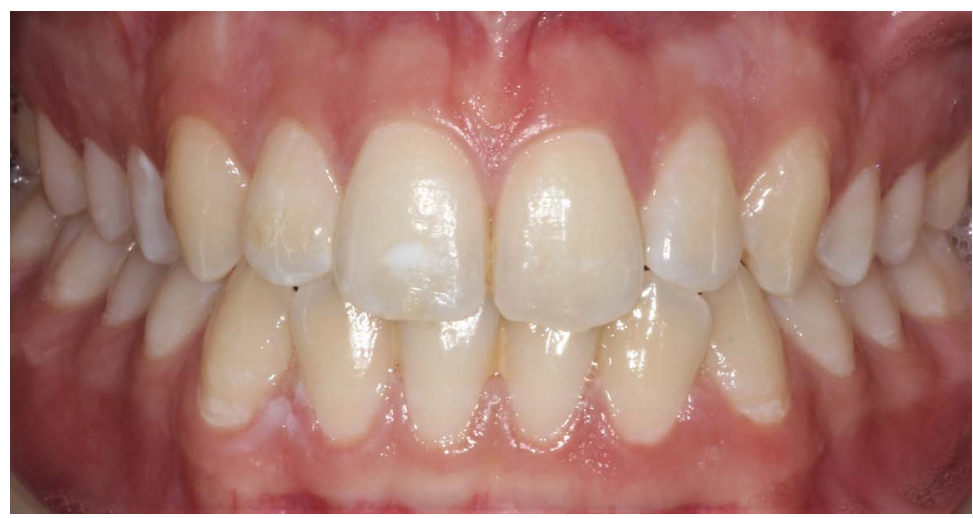

Figure 24. Patient 8 before.

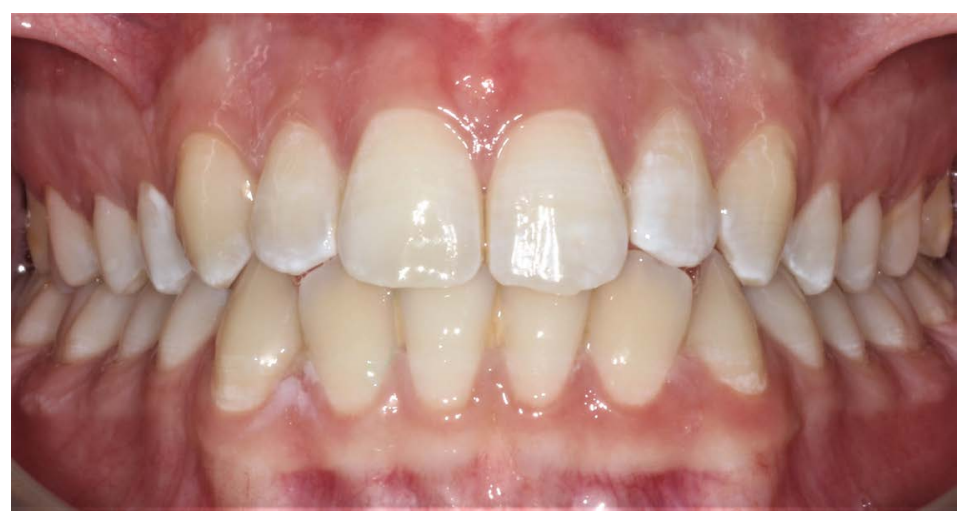

Figure 25. Patient 8 after. 


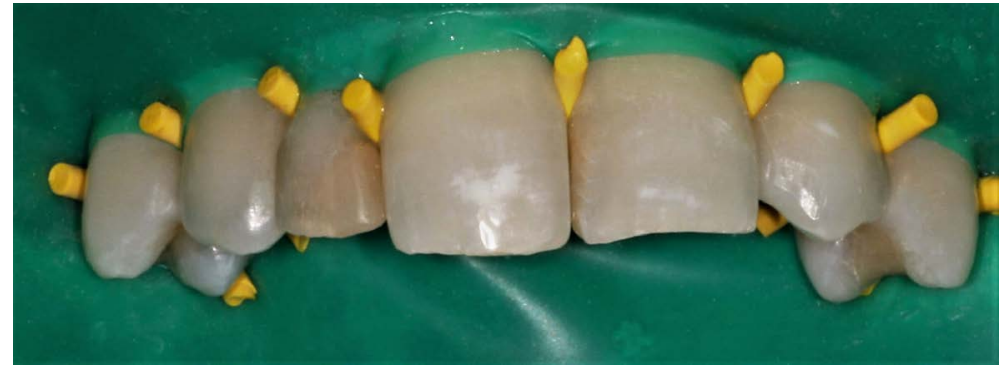

Figure 26. Patient 9 before.

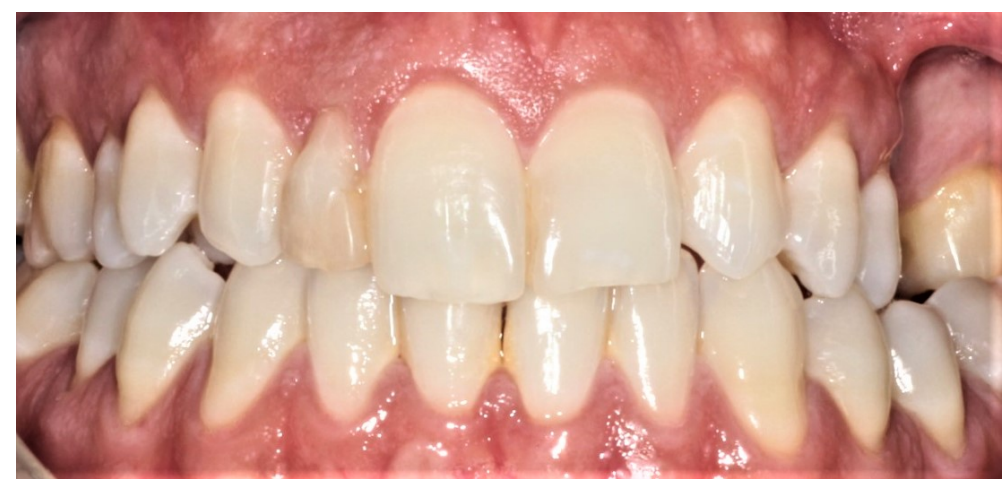

Figure 27. Patient 9 after.

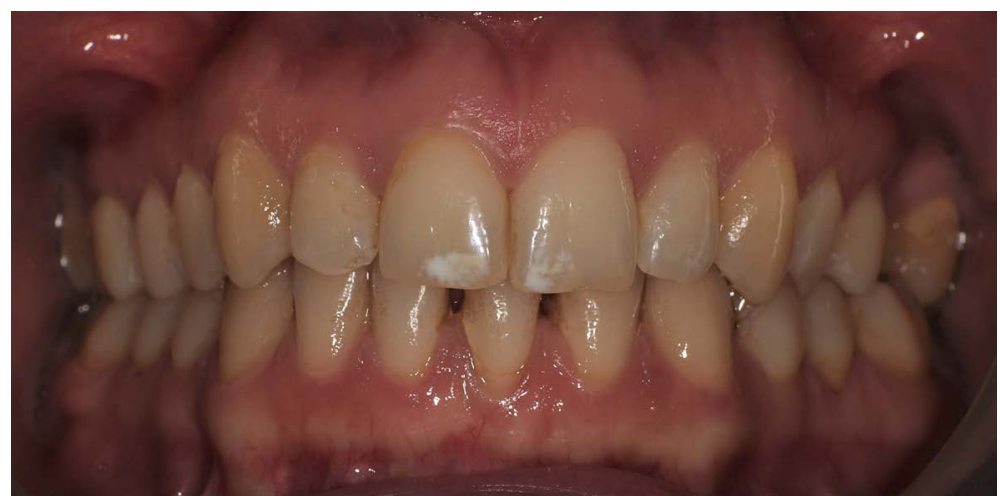

Figure 28. Patient 10 before.

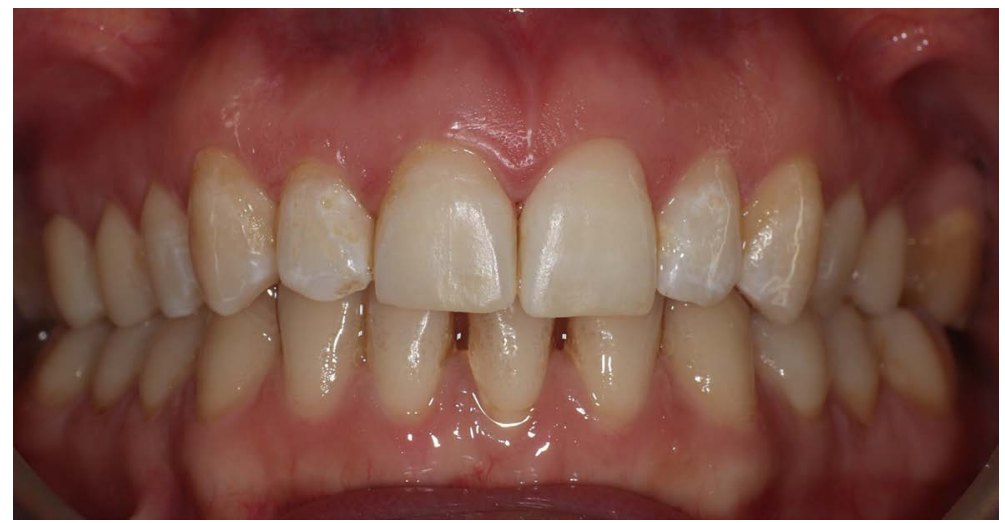

Figure 29. Patient 10 after. 


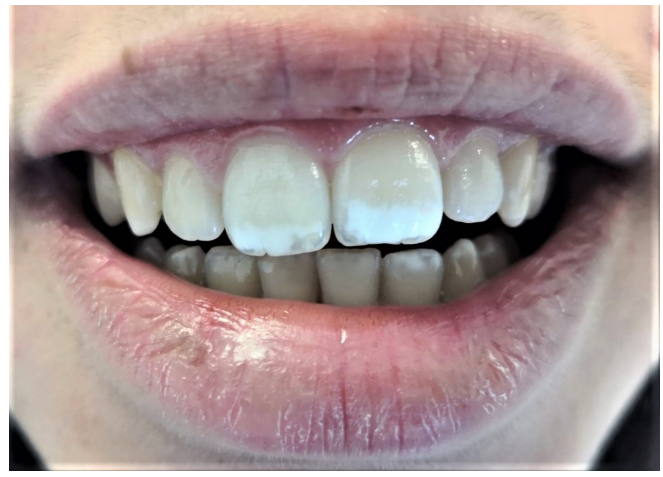

Figure 30. Patient 11 before.

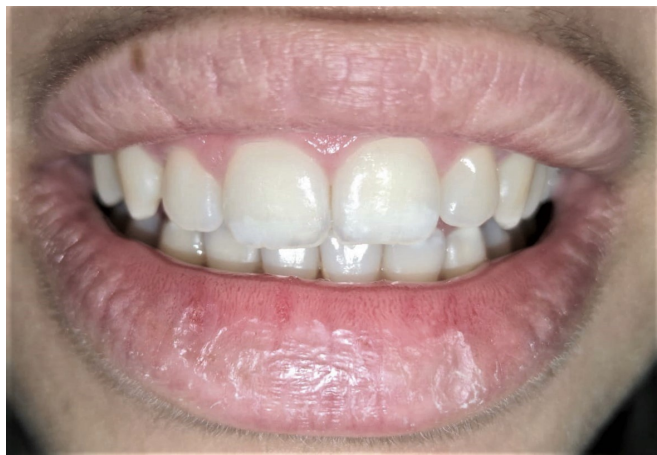

Figure 31. Patient 11 after.

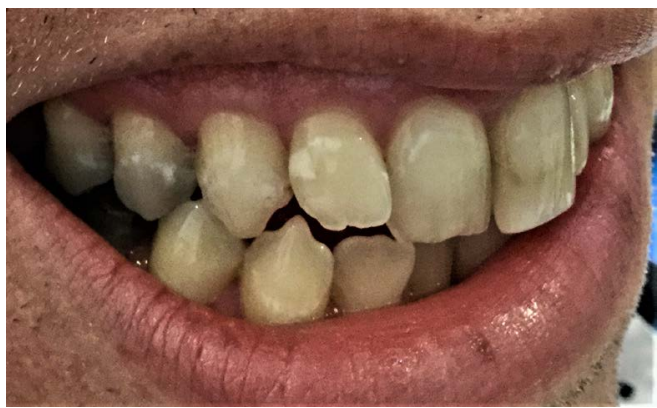

Figure 32. Patient 12 before.

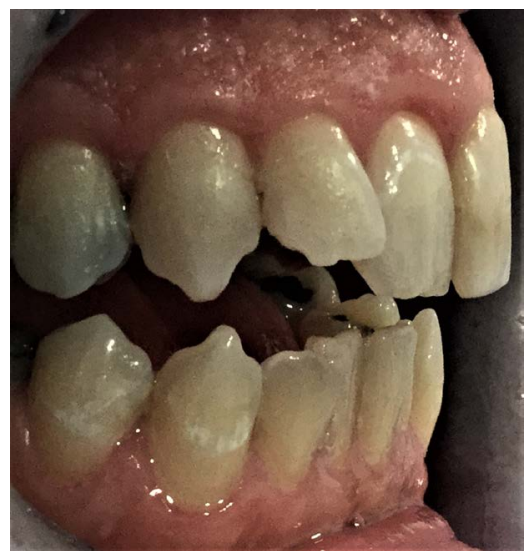

Figure 33. Patient 12 after. 


\subsection{Maintaining the Integrity of the Specifications}

The template is used to format your paper and style the text. All margins, column widths, line spaces, and text fonts are prescribed; please do not alter them. You may note peculiarities. For example, the head margin in this template measures proportionately more than is customary. This measurement and others are deliberate, using specifications that anticipate your paper as one part of the entire journals, and not as an independent document. Please do not revise any of the current designations.

\section{Discussion}

Nowadays, more and more patients turn to professionals of the dental sector for aesthetic, for this reason, even small imperfections such as WSL can be perceived by the patient as a highly invalidating problem in the field of smile aesthetics. Low viscosity resin infiltration therapy is now widely used and studied in daily dental practice, the removal of the surface enamel is carried out by means of an acid, the $15 \%$ hydrochloric acid. It allows an adequate removal of the pseudoimpact layer favoring the deep penetration of the resin. The infiltrating resin based on TEDMA, being not very viscous manages to penetrate deeply inside the porosity of the lesion, improving the aesthetic impact and the index of light refraction. Moreover it increases the dental hardness compared to the injured tooth and promotes a long-term reduction of surface roughness (Yazkan, 2018). Using the right protocol and adequate preventive measures, this type of therapy allows an excellent aesthetic result, even in the long-term. This therapy is simpler and more practical than the conventional therapies used today (Senestraro, 2013). The particularly favorable aspect is given by the fact that this type of therapy seems to give extraordinary results as regards the prevention of carious pathology even after many years from the application (Yoo et al., 2018). In our work, the low viscosity resin infiltration therapy gave excellent aesthetic results in 12 out of 17 lesions, in the lesions where there weren't complete remission, an excellent aesthetic improvement and a good reduction of the lesion visibility has been obtained.

Long-term control could improve the aesthetic result following a better rehydration of hard tissues.

All patients were satisfied with the outcome of the treatment.

In cases of incomplete resolution, the association with microabrasion could probably improved the final aesthetic result by favoring a better penetration of the infiltration resin and returning a further better aesthetic appearance.

A better evaluation method of the lesions could certainly improve the therapeutic appropriateness and better select the cases in order to obtain a complete success of each type of lesion.

\section{Conclusion}

According to the bibliography, the cases treated in this article through the use of low density micro-infiltrative resin gave excellent results in a high percentage of WSL, 12 out of 17 treated [28]. While in those not completely resolved it allowed 
a high aesthetic improvement compared to the pre-treatment condition. Future studies are needed to increase the sample of treated patients and evaluate the long-term behavior of these materials.

\section{Authors' Contributions}

Conceptualization, D.A. and R.P.; Methodology, D.A. and R.P.; Software, D.A.; Validation, M.M.F. and S.P.; Formal Analysis, S.S.; Investigation, D.A. and R.P.; Resources, D.A.; Data Curation, R.P.; Writing-Original Draft Preparation, D.A.; Writing-Review \& Editing, D.A.; Visualization, S.S.; Supervision, S.P. and M.M.F.; Project Administration, S.P.

\section{Conflicts of Interest}

The authors declare no conflicts of interest regarding the publication of this paper.

\section{References}

[1] Sampsonm, A., Jeremiah, H.G., Andiappan, M. and Newton, J.T. (2020) The Effect of Viewing Idealised Smile Images Versus Nature Images via Social Media on Immediate Facial Satisfaction in Young Adults: A Randomised Controlled Trial. Journal of Orthodontics, 47, 55-64. https://doi.org/10.1177/1465312519899664

[2] Tjan, H.L., Miller, G.D. and The, J.G.P. (1984) Some Esthetic Factors in a Smile. Journal of Prosthetic Dentistry, 51, 24-28.

https://doi.org/10.1016/S0022-3913(84)80097-9

[3] Joiner, A. (2010) Whitening Toothpastes: A Review of the Literature. Journal of Dentistry, 38, e17-e24. https://doi.org/10.1016/j.jdent.2010.05.017

[4] Denis, M., Atlan, A., Vennat, E., Tirlet, G. and Attal, J.-P. (2013) White Defects On Enamel: Diagnosis and Anatomopathology: Two Essential Factors for Proper Treatment (Part 1). International Orthodontics, 11, 139-165.

https://doi.org/10.1016/j.ortho.2013.02.014

[5] Borges, A.B., Caneppele, T.M., Masterson, D. and Maia, L.C. (2017) Is Resin Infiltration an Effective Esthetic Treatment for Enamel Development Defects and White Spot Lesions? A Systematic Review. Journal of Dentistry, 56, 11-18. https://doi.org/10.1016/j.jdent.2016.10.010

[6] Beltran-Aguilar, E.D., Barker, L. and Dye, B.A. (2010) Prevalence and Severity of Dental Fluorosis in the United States, 1999-2004. NCHS Data Brief, 53, 1-8.

[7] Dean, H.T. (1934) Classification of Mottled Enamel Diagnosis. The Journal of the American Dental Association (1922), 21, 1421-1426. https://doi.org/10.14219/jada.archive.1934.0220

[8] Chawla, N., Messer, L.B. and Silva, M. (2008) Clinical Studies on Molar-Incisor Hypomineralisation. Part 2: Development of a Severity Index. European Archives of Paediatric Dentistry, 9, 191-199. https://doi.org/10.1007/BF03262635

[9] Giuca, M.R., Lardani, L., Pasini, M., Beretta, M., Gallusi, G. and Campanella, V. (2020) State-of-the-Art on MIH. Part.1 Definition and Aepidemiology. European Archives of Paediatric Dentistry, 21, 80-82.

[10] Kleter, G.A. (1998) Discoloration of Dental Carious Lesions (A Review). Archives of Oral Biology, 43, 629-632. https://doi.org/10.1016/S0003-9969(98)00048-X 
[11] Khoroushi, M. and Kachuie, M. (2017) Prevention and Treatment of White Spot Lesions in Orthodontic Patients. Contemporary Clinical Dentistry, 8, 11-19. https://doi.org/10.4103/ccd.ccd_216_17

[12] Sundararaj, D., Venkatachalapathy, S., Tandon, A. and Pereira, A. (2015) Critical Evaluation of Incidence and Prevalence of White Spot Lesions during Fixed Orthodontic Appliance Treatment: A Meta-Analysis. Journal of International Society of Preventive and Community Dentistry, 5, 433-439. https://doi.org/10.4103/2231-0762.167719

[13] Paduano, S., Rongo, R., Bucci, R., Aiello, D., Carvelli, G., Ingenito, A., Cantile, T. and Ferrazzano, G.F. (2018) Is There an Association between Various Aspects of Oral Health in Southern Italy Children? An Epidemiological Study Assessing Dental Decays, Periodontal Status, Malocclusions and Temporomandibular Joint Function. European Journal of Paediatric Dentistry, 19, 176-180.

[14] Gorelick, L., Geiger, A.M. and Gwinnett, A.J. (1982) Incidence of White Spot Formation after Bonding and Banding. American Journal of Orthodontics, 81, 93-98. https://doi.org/10.1016/0002-9416(82)90032-X

[15] Boersma, J.G., Van Der Veen, M.H., Lagerweij, M.D., Bokhout, B. and Prahl-Andersen, B. (2005) Caries Prevalence Measured with QLF after Treatment with Fixed Orthodontic Appliances: Influencing Factors. Caries Research, 39, 41-47. https://doi.org/10.1159/000081655

[16] Tufekci, E., Dixon, J.S., Gunsolley, J.C. and Lindauer, S.J. (2011) Prevalence of White Spot Lesions during Orthodontic Treatment with Fixed Appliances. Angle Orthodonist, 81, 206-210. https://doi.org/10.2319/051710-262.1

[17] Dikmen, B. (2015) ICDAS II Criteria (International Caries Detection and Assessment System). Journal of Istanbul University Faculty of Dentistry, 49, 63-72.

[18] Ekstrand, K.R., Gimenez, T., Ferreira, F.R., Mendes, F.M. and Braga, M.M. (2018) The International Caries Detection and Assessment System-ICDAS: A Systematic Review. Caries Research, 52, 406-419. https://doi.org/10.1159/000486429

[19] Meng, Z., Yao, X.S., Yao, H., Liang, Y., Liu, T., Li, Y., Wang, G. and Lan, S. (2009) Measurement of the Refractive Index of Human Teeth by Optical Coherence Tomography. Journal of Biomedical Optics, 14, Article ID: 034010. https://doi.org/10.1117/1.3130322

[20] Peters, M.C., Jr. Hopkins, A.R. and Yu, Q.Z. (2018) Resin Infiltration: An Effective Adjunct Strategy for Managing High Caries Risk-A within-Person Randomized Controlled Clinical Trial. Journal of Dentistry, 79, 24-30. https://doi.org/10.1016/j.jdent.2018.09.005

[21] Khan, S.Z., Kaleem, M., Din, S.U., Khan, H.A. and Qureshi, S.W. (2019) The Current Use of Anti-Cariogenic Agents and Fluoride Agents to Cure Write Spot Lesion: A Systematic Analysis. Journal of the Pakistan Medical Association, 69, 1876-1882.

[22] Tao, S.Y., Zhu, Y., Yuan, H., Tao, S.B., Cheng, Y.M., Li, J.Y. and He, L.B. (2018) Efficacy of Fluorides and CPP-ACP vs Fluorides Monotherapy on Early Caries Lesions: A Systematic Review and Meta-Analysis. PloS One, 13, Article ID: e0196660. https://doi.org/10.1371/journal.pone.0196660

[23] Philip, N. and Walsh, L. (2019) The Potential Ecological Effects of Casein Phosphopeptide-Amorphous Calcium Phosphate in Dental Caries Prevention. Australian Dental Journal, 64, 66-71. https://doi.org/10.1111/adj.12661

[24] Goldstein, R.E. (1997) In-Office Bleaching: Where We Came from, Where We Are Today. Journal of the American Dental Association, 128, 11S-15S. https://doi.org/10.14219/jada.archive.1997.0415 
[25] Sonesson, M., Bergstrand, F., Gizani, S. and Twetman, S. (2017) Management of Post-Orthodontic White Spot Lesions: An Updated Systematic Review. European Orthodontic Society, 39, 116-121. https://doi.org/10.1093/ejo/cjw023

[26] Di Giovanni, T., Eliades, T. and Papageorgiou, S.N. (2019) Interventions for Dental Fluorosis, an Endemic Disease: A Systematic Review. Journal of Family Medicine and Primary Care, 8, 3108-3113. https://doi.org/10.4103/jfmpc.jfmpc_648_19

[27] Yetkiner, E., Wegehaupt, F., Wiegand, A., Attin, R. and Attin, T. (2014) Colour Improvement and Stability of White Spot Lesions Following Infiltration, Micro-Abrasion, or Fluoride Treatments in Vitro. The European Journal of Orthodontics, 36, 595-602. https://doi.org/10.1093/ejo/cjt095

[28] Senestraro, S.V., Crowe, J.J., Wang, M., Vo, A., Huang, G., Ferracane, J. and Covell, D.A. (2013) Minimally Invasive Resin Infiltration of Arrested White-Spot Lesions: A Randomized Clinical Trial. Journal of the American Dental Association, 144, 997-1005. https://doi.org/10.14219/jada.archive.2013.0225 